\title{
Evaluating the Planning and Development Phase of a Demonstration Project: At Home / Chez Soi Moncton
}

\author{
Linsay Flowers, Charles Gaucher, and Jimmy Bourque \\ Université de Moncton
}

\begin{abstract}
This research focused on the planning and development phase of the Moncton site of At Home / Chez Soi, a multisite research demonstration project funded by the Mental Health Commission of Canada, developed to test an innovative approach to working with homeless people living with severe and persistent mental illness in 5 Canadian cities. Using qualitative methods, 11 local key informants participated in semistructured interviews focusing on: (a) early planning processes; (b) principles and values guiding the planning process; (c) planning actions; and (d) stakeholder relationships. We found that contextual elements, especially those related to the small size and bilingual nature of the city and the lack of mental health services in the area, had a significant impact on the planning and development of the project in Moncton. The implications of findings for future planning of complex community interventions are noted.
\end{abstract}

Keywords: planning, mental health, homelessness, multisite complex community interventions, service evaluation

\section{RÉSUMÉ}

La présente étude fut menée dans le cadre du projet de démonstration pancanadien At Home / Chez Soi, financé par la Commission de la santé mentale du Canada, mis au point pour évaluer une approche novatrice pour intervenir auprès de personnes sans-abri souffrant d'un problème de santé mentale. Elle a pour objectif d'explorer la phase de planification et développement dans un des 5 sites, soit Moncton.

Linsay Flowers and Charles Gaucher, School of Social Work, Université de Moncton; Jimmy Bourque, Faculty of Education, Université de Moncton.

We thank Jayne Barker (2008-11), Cameron Keller (2011-12), and Catharine Hume (2012-present), Mental Health Commission of Canada, At Home / Chez Soi National Project Leads, and Paula Goering, At Home / Chez Soi National Research Lead, National Research Team; as well as the five site research teams, site coordinators, and numerous service and housing providers. We also thank persons with lived experience who have contributed to this project and the research. This research has been made possible through a financial contribution from Health Canada to the Mental Health Commission of Canada. The Mental Health Commission of Canada oversaw the design and conduct of the study and has provided training and technical support to the service teams and research staff throughout the project. The views expressed herein solely represent those of the authors.

Correspondence concerning this article should be addressed to: Linsay Flowers, 5 Meghan St., Riverview, NB, E1B 4E4. Email: els4004@umoncton.ca 
En utilisant des méthodes qualitatives, 11 informateurs et informatrices clés ont participé à des entrevues semi-dirigées axées sur (a) les processus de planification précoce, (b) les principes et les valeurs guidant le processus de planification, (c) les actions de planification et (d) les relations entre les parties intéressées. Nous avons constaté que les éléments contextuels, en particulier ceux liés à la taille et la nature bilingue de la ville ainsi qu'une lacune importante en matière de services de santé mentale dans la région, ont eu un impact significatif sur la planification et le développement du projet à Moncton. Les conséquences des résultats pour la planification de futures interventions sont notées.

Mots clés : planification, santé mentale, itinérance, interventions communautaires complexes, évaluation des services

\section{INTRODUCTION}

Recent years have revealed a steady decline in the amount of social assistance benefits, social programs, available subsidized housing units, as well as insufficient increases in the minimum wage, making it increasingly difficult for society's most vulnerable populations to access and maintain affordable housing (Fédération canadienne des municipalités, 2011; Gaetz, 2010). As a result, homelessness has emerged as a significant social problem affecting thousands of Canadians, with estimates of prevalence ranging from 150,000 to 300,000 (Parliament of Canada, 2012).

A disproportionate number of persons experiencing homelessness live with some form of mental illness (Aubry, Klodawsky, \& Coulombe, 2012; Hulchanski, Campsie, Chau, Hwang, \& Paradis, 2009). In fact, "the percentage of Canadians who are living with mental illness who need access to [adequate, appropriate, and affordable] housing is almost double the percentage of people in the general population whose housing needs are not being met" (Hulchanski et al., 2009). Padgett, Gulcur, and Tsemberis (2006) point out that suitable housing alone would not fulfill the needs of this population. Individuals living with mental illness also require "an array of support services" (p.75) in order to live independently. The most effective way to deliver these services, however, remains a point of contention in the field (Nelson, 2010). Nelson, Aubry, and Lafrance (2007) argue that clients find it difficult to identify with traditional "treatment first" approaches to service delivery, in that these approaches are most often abstinence-based with professionals imposing a great deal of structure and control.

In light of these issues, the Mental Health Commission of Canada developed the At Home / Chez Soi demonstration project, a multisite study of Housing First (HF) approaches implemented in Vancouver, Winnipeg, Toronto, Montreal, and Moncton. HF is an innovative approach to working with homeless people premised on the notion that housing is a basic human right, and therefore should not be denied to anyone. As such, robust support services predicated on assertive engagement, not coercion, are provided in addition to housing, in an effort to support successful community reintegration (Nelson, 2010). This five-year study was intended to evaluate the efficiency and cost-effectiveness of this approach for people with severe and persistent mental illness and a history of chronic homelessness (Mental Health Commission of Canada, 2012).

Health and social problems such as mental illness and homelessness are complex, culturally-situated, and influenced by factors at multiple levels of analysis, and therefore require complex, multicomponent 
community interventions (Nelson et al., 2013; Trickett, 2009). In planning such interventions, particular attention must be paid to policies that may influence program adoption (Raghavan, Bright, \& Shadoin, 2008). Sustainability is another key, yet often neglected, aspect of the planning process. Program innovations often focus primarily on successful implementation, ignoring assurances of sustainability after funding for the trial has ended (Johnson, Hays, Center, \& Daley, 2004).

Program evaluation is a systematic approach to collecting, analyzing, and using information to assess social programs (Greene, 1994) in order to inform stakeholders whether programs are both effective and efficient. Process evaluation documents analyze the early development of a strategy or program, assessing whether the program is being implemented as planned (Rossi, Lipsey, \& Freeman, 2004). While the evaluation of multisite, complex interventions has gained interest over the past years (e.g., Dewa, Durbin, Wasylenki, Ochocka, Eastabrook, Boydell, \& Goering, 2002; Katz, Murimi, Gonzalez, Njike, \& Green, 2011; King, Ross, Callow-Heusser, Gillickson, Lawrenz, \& Weisz, 2011), relatively few studies have addressed the planning of such interventions. Sylvestre, Pancer, Brophy, and Cameron (1994) conducted a qualitative study on the relationship between government and community stakeholders in the planning of a multisite, complex, health promotion/prevention research demonstration project for children living in disadvantaged communities in Ontario. More recently, Nelson and colleagues (2013) studied the relationships between the At Home / Chez Soi national team and the five project sites across Canada in planning a complex community intervention. Neither of the above-mentioned studies, however, addresses the planning process at the local level.

This paper focuses on the findings that emerged from an examination of the planning and development phase of the Moncton site. The purpose of this research is to provide an in-depth description of lessons learned that can be useful for planners and practitioners in other jurisdictions who are involved in similar initiatives. This evaluation also aims to help the key players reflect on and understand the underlying causes of the issues they would inevitably have to face.

\section{METHOD}

\section{At Home / Chez Soi Research and Intervention Model}

At Home / Chez Soi used a pragmatic, multisite field trial research design. Participants who met the predefined criteria (aged 18 or older, absolutely homeless or precariously housed, and having a serious mental disorder) were randomized into two groups, an experimental group and a treatment-as-usual (TAU) group. The TAU group received the same services and supports they would have been able to access in the absence of the demonstration project. The experimental group received client-centered services that included access to regular housing with "no strings attached" (Padgett et al., 2006) and an array of services offered by a multidisciplinary Assertive Community Treatment (ACT) or Intensive Case Management (ICM) team based on individual need (Nelson, Aubry, \& Lafrance, 2007).

\section{Moncton Site}

Each of the five participating sites was chosen based on its ability to contribute to a better understanding of the target population's needs in a variety of different contexts. Several aspects of Moncton's particular situation were related to the decision to include this city. 
The Greater Moncton area, comprised of three small cities (Moncton, Dieppe, and Riverview), is located in the southeastern region of the province of New Brunswick. With a total population of approximately 139,000, it is considered a region with a low-density population (City of Moncton, 2012). It is much smaller than the other four sites, all of which are large urban centres. Situated in Canada's only constitutionally bilingual province (Department of Justice Canada, 2012), 65\% of its citizens report their mother tongue as English and 34\% as French (Statistics Canada, 2007). In light of the city's bilingual nature, a resolution was passed in 2002 making Moncton the first municipality in Canada to be declared officially bilingual by its municipal council (City of Moncton, 2002).

According to Experiencing homelessness: The sixth report card on homelessness developed by the Greater Moncton Homelessness Steering Committee (2013), it is estimated that approximately 500 different people stayed in one of the two emergency shelters for homeless individuals in 2011. However, this estimate represents only the absolutely homeless and does not include the "hidden homeless, those who are moving continuously from one housing arrangement to another" (p. 6). As well, up to 15,000 individuals in Moncton have been identified as being at risk for homelessness through living in substandard rental units or experiencing significant financial demands related to covering their basic shelter and living costs (Human Resources and Social Development Canada, 2007). According to Gaucher, Albert, Savoie, \& Bâ (2010), homeless persons living outside of large urban centers are less visible than their urban counterparts. Moreover, homelessness in remote areas cannot be characterized strictly by the absence of a residence, but rather by frequent changes of residence (i.e., residential instability or insecurity) (Roy, Hurtubise, Bélanger, Lemetayer, Morin, \& Morin, 2003). A community's size, structure, and population density all contribute to the fact that homelessness manifests itself differently and less visibly in rural than in more densely populated areas.

Despite the fact that Moncton is much smaller than the other sites, the city experienced a 9.7\% population growth between 2006 and 2011. The region has seen an influx of people, in particular from the northern parts of the province, looking for employment. Others have migrated toward the community in search of health and mental health services. The ever-increasing population has created a demand that existing services are unable to fulfill (Human Resources and Social Development Canada, 2007). Moncton's unique context enabled the evaluation of HF in a small but rapidly growing bilingual city with a shortage of mental health services.

\section{Research and Intervention Design}

A total of 201 homeless or precariously housed persons with severe and persistent mental disorders were randomly assigned to either HF or TAU groups. The HF group was comprised of 100 participants and the TAU group, 101 participants, all of whom were followed over a 24-month period. In addition, a total of 41 individuals were recruited from South-East New Brunswick, an adjoining rural area, to participate in a small substudy. The research design for this substudy was quasi-experimental. Twenty-four individuals with serious mental illness were assigned to receive HF, and a group of 17 individuals, matched as well as possible on sex and housing status, were assigned to a control group. Mixed methods were used in the study to collect both quantitative and qualitative data. 


\section{Evaluation of the Planning and Development Phase}

Data collection. Data collection was initiated by meeting the people identified as key to the development of the site's project so as to produce a chronology of events and better understand the local organizational structure. Once the research team had received approval from the ethics committees at l'Université de Moncton and the University of Ottawa, a list of potential respondents was established, starting with the site coordinator's suggestions and proceeding with the "snowball" technique. People from the nonprofit sector and the government, as well as scholars, were interviewed with a particular effort to maintain a balance between women and men, and between francophones and anglophones.

From November 2009 to March 2010, 11 semistructured interviews were conducted by a small team of interviewers, who covered four main aspects of the planning phase set forth by the national team: (1) early planning processes; (2) principles and values guiding the planning process; (3) planning actions; and (4) stakeholder relationships. The interview outline was adjusted as the project evolved. Approximately 12 hours of interviews were transcribed according to protocol in preparation for analysis.

Data analysis. Preliminary information was compiled, including some 200 pages of verbatim transcripts, a timeline, and an organizational chart developed through an iterative process of observation, discussion, and data formatting. Next, the research team conducted a thematic analysis, grouping the information according to the general themes covered during the interviews (Fereday \& Muir-Cochrane, 2008). QSR NVivo8 software was used to compile and codify data, after which a descriptive synthesis of the major categories was done based on the categories that emerged. A cross-reading of the data was conducted, allowing the research team to highlight inconsistencies within certain themes, emphasizing the subjective nature of some comments. Findings were presented on two separate occasions, first to all members of Moncton's research team and again during a research meeting to which both researchers and community members were invited.

\section{FINDINGS}

\section{Identification of the Target Population and Definitional Issues}

The original criteria set forth by the national team with regard to participant inclusion stipulated that participants must be either absolutely homeless or precariously housed. They must have had no fixed place to stay for more than seven nights and little likelihood of obtaining accommodation in the upcoming month or they must live in a single room occupancy (SRO) (rooming house or hotel/motel) and have had two or more episodes of being absolutely homeless in the past year. However, certain contextual elements contribute to the fact that the face of homelessness in Moncton differs from that of larger metropolitan areas: "It's just not that visible, we don't have a ton of people sleeping on the city streets, we don't have a ton of people panhandling and squeegeeing and loitering" (Key player 23, 2010). The project's initial design would have excluded the following: those living temporarily with friends or families; those in transition; those temporarily without a dwelling; and those living in long-term institutions (i.e., special care homes), all of which are precarious living situations common to the Moncton area:

Les sans-abris c'est quelqu'un qui fait du sofa à sofa, c'est quelqu'un qui est dans un foyer de soins spéciaux, qui ne devrait pas être là. C'est les personnes qui couchent en prison parce qu'ils n'ont pas de domicile. Ce n'est pas nécessairement quelqu'un dans une boîte de carton nécessairement. (Key player 02, 2010) ${ }^{1}$ 
The discordance between the stereotypical vision of homelessness and the local reality was problematic in the planning phase of the project, in that there was concern that it would not be possible to identify enough participants to implement the project. Key players were forced to advocate for selection criteria better suited to the region's reality. The request was examined by the national research team, which was faced with the challenge of ensuring consistency across the sites in terms of the target population and ultimately in terms of producing comparable research results. In the end, the national team allowed a small number of exceptions relating to individuals living in inadequate housing and qualifying for the study as precariously housed. As well, early in the study the criteria for being precariously housed for all the sites was expanded so that individuals living in an SRO, rooming house, or hotel/motel with a history of one episode of homelessness of at least four weeks duration were also eligible.

It was clearly stated in the request for proposal formulated by the Mental Health Commission that an advisory committee be put in place in each site to provide input on local adaptations to the project within the constraints of the national guidelines. The participation of persons with lived experience was explicitly requested. However, early definitional difficulties in Moncton made it challenging to find suitable people with lived experience for the advisory committee. Implementation of the advisory committee was delayed, thus limiting the early involvement of persons with lived experience in the decision-making processes.

\section{Centralization of Coordination Efforts and Effects on Key Community Players}

Delays in the implementation of formal governing structures in Moncton resulted in coordination efforts with regard to the initiation process that were highly centralized, and that both helped and hindered the process. In the beginning, extensive consultations were held within the community. Despite the fact that a variety of individuals were consulted, few besides the site coordinator were involved in the overall planning and development of the project: "I think she took way too much on herself; that definitely led to some confusion" (Key player 16, 2010).

It is important to note the reverence with which key players spoke of the site coordinator, stating that she is as well respected in the community as she is well known. One explained that she was granted full trust for the task at hand: "This community has a lot of faith in [local coordinator] in terms of her skills and abilities but more importantly, in terms of getting everybody together, you know, getting everybody on side" (Key player 21, 2010). Key players were identified, called to participate, and assigned a role by the coordinator according to their ability and willingness to contribute.

The coordinator's knowledge, influence, and enthusiasm proved to be highly advantageous to the development of the local project, first and foremost in that she had strong connections at both community and government levels: "You've got someone who is well respected, [has] tremendous connections into the community both of the political and personal nature" (Key player 14, 2010). Connections at the government level allowed her to navigate the otherwise impenetrable complex of bureaucratic structures with a certain ease. It is due to these connections that project elements were able to be integrated into existing frameworks, consequently making them more secure than if they had stood alone. Moreover, her long history of active community involvement brought with it a great deal of confidence on the community's behalf: 
Je pense qu'il y a eu une grande, grande ouverture au niveau de la communauté aussi, autant des agences communautaires. Je pense que ça aidé énormément dans le sens que ces agences-là la connaissaient déjà, ça aidé énormément à faire la liaison et d'accepter l'ouverture de s'impliquer dans un projet comme ça. (Key player 18, 2010) $)^{2}$

Community organizations embarked on the project without hesitation, fully trusting the coordinator's ability to create a project that would benefit their clientele and the service network.

It was not solely her ability to target and draw in influential people in the community, however, that proved to be of benefit to the planning and development process. The long list of causes to which she had been devoted over the years, paired with her experience in politics, provided her with extensive knowledge with regard to local context: "Elle savait avec son experience communautaire, mais surtout avec son expérience à Ottawa, elle savait maintenant comment le système travaillait" (Key player 01, 2009). ${ }^{3}$ She was able to use this knowledge to call for modifications to the original plans. Key player 16, for example, explains that although the Mental Health Commission's original intent was to implement an ICM team in Moncton, "it was felt that we just had such a shortage of services that the needs were extremely high in our population of homeless and mentally ill. They wanted the site coordinator to advocate for an ACT team, which she did" (2010). Key player 01 added that although there was resistance on the Mental Health Commission's behalf for budgetary reasons, the site coordinator refused to take no for an answer:

[Elle était] comme: « Ok, vous ne pouvez pas me donner un ICM? Vous ne pouvez pas me donner la moitié de l'équipe dont j'ai besoin. On ne peut pas faire la job parce qu'on n'a pas le support. Si tu ne nous donnes pas tout le staff dont on a besoin, on ne peut pas le faire. » (2009)

Although the centralization of coordination efforts was beneficial to certain aspects of the planning process, it was equally problematic for others. One key player clearly stated that participation in the process was fragmented, meaning that most players' contribution was limited to a small portion of the process: "Je te dis mon implication, je suis autour de la table, [mais] mon implication à la planification est vraiment limitée" (Key player 02, 2010). ${ }^{5}$ The majority of key players ultimately did not see themselves as such. The research team was able to deduce, in spite of limited information about certain aspects of the planning, that the centralization of the coordination efforts also had certain negative consequences in terms of the research and service components of the demonstration project. For example, due to New Brunswick's bilingual nature and a longstanding tension between the two linguistic communities, the provincial health care system was divided into two regional health authorities, one primarily anglophone and the other primarily francophone. As per one key player, the former authority was called to participate in the planning and development process in its earliest stages; the latter, however, due to an oversight on the site coordinator's behalf, was not. This lack of inclusion created tension between key and potential key players, and in the end necessitated the reorganization of certain structures that had already been put in place.

\section{Obstacles Related to the Inclusion of a Control Group in the Development of the Methodology}

The design of the research project, essentially quantitative in nature, implied the division of participants into two groups; however, due to the scarcity of resources and services in Moncton, this constituted an ethical issue for key players on all ends of the spectrum: 
On parlait du groupe de contrôle, puis la discussion a été: « Oui, puis les 100 personnes sur le groupe de contrôle auront les services as usual. » Ensemble, en même temps, et avec le même mal dans leur visage, les personnes ont tous dit: « Il y en a pas de services. » (Key player 01, 2009) ${ }^{6}$

Actors began questioning the ethics of recruiting potential participants, offering hope with regard to bettering their situation only to return half of it back to inadequate living arrangements and long waiting lists for mental health services. Although some people were able to understand the decision on an intellectual level, few were able to reconcile it on an emotional level: "I think in their mind, in the cognitive part of their brain, they understood the need for it but in the compassionate part of themselves, they felt that it's just so hard to do" (Key player 20, 2010).

One key player felt that the process might be detrimental to the well-being of clients randomized to the control group: "The clients actually go downhill after they are randomized to the control, they don't come out at the same level on the other side, they actually go downhill because of this whole process" (Key player 16, 2010). Certain actors went so far as to question their involvement in the project. The research team who drafted the original proposal was superseded by a completely different team shortly after its submission to the Mental Health Commission of Canada. As per one key player, the chosen methodology was among the reasons for which the original research team withdrew from the project: ${ }^{7}$

[Le chercheur] était supposé de toute mener la recherche, il y avait beaucoup de grosses questions au niveau du groupe contrôle. Là, il a décidé qu'il était incapable de faire. (Key player 01, 2009) ${ }^{8}$

Members of the research team to follow were equally troubled: "I mean nobody wants to turn anyone down. You're not the one that wants to say you've been randomized to care as usual" (Key Player 20, 2010).

Furthermore, it was noted that the site coordinator's limited experience in this field and pressing concern for the target population made it difficult for her to understand the experimental nature of the initiative and therefore to respect the guidelines set forth by the national team: "[She] is not from a science background, so I think it's harder for her to see a study per se and having inclusion criteria, so it caused conflict" (Key player 16, 2010). Although the implementation of a control group proved to be problematic in this particular context, there was little to no flexibility on the national team's behalf: "La commission, eux autres, ils insistaient énormément pour qu'il ait un groupe contrôle pour justement une preuve un petit peu plus convaincante, avoir plus d'appui" (Key player 18, 2010). ${ }^{9}$ This resistance rendered the planning even more complex, even though it gave the local team the opportunity to reflect on ethical issues related to exclusioninclusion of participants.

\section{Concerns Surrounding Sustainability and Their Influence on the Planning and Development Process}

Although the national team was not swayed by the heated ethical debate in terms of implementing a control group in Moncton, concern surrounding the apparent lack of services became the foundation on which the Moncton research demonstration project was built. A great deal of effort was put into ensuring the success and consequently the continuation of the services being put in place after the five-year term:

In light of the problematic gaps in service, the main objective became the sustainability of services to be implemented within the project. In 2013, we want a seamless interface so the project now becomes a regular 
part of the system of meeting the needs of vulnerable people in Moncton who are homeless. (Key player $14,2010)$

The national team, on the other hand, felt it more important to emphasize the exploratory nature of the project: "The commission didn't come to us and start at the front saying, 'Let's plan for how this can continue on' and 'What happens if the research says it's a failure?"' (Key player 20, 2010).

One key player explained that, although it may have been easier to work in a community-based capacity, the site coordinator negotiated the integration of as many project elements as possible directly into existing governmental structure so as to ensure a stability that community organizations could not provide:

Ça aurait été beaucoup moins cher et beaucoup plus facile d'embaucher au communautaire pour les services. Les gens dans les organismes communautaires auraient embarqué dans l'équipe vite et ça serait fait avec beaucoup moins de maux de tête. Mais, on se disait « oui, on peut faire ça comme ça, mais à la fin de quatre ans c'est qui va être là pour nous supporter? C'est qui, qui va être là pour aller parler au gouvernement pour leur dire il faut que ça continue. » (Key player 01, 2009) ${ }^{10}$

The service team consisted of professionals hired through the regional health authorities, ensuring both quality and sustainability. They remained employees of the regional health authority for which they worked; salaries, benefits, and seniority remained intact. This ensured lower employee turnover and therefore more consistent services to users. Furthermore, rent subsidy provided to participants was integrated into New Brunswick's social housing framework. The integration of these elements into a pre-existing and secure system would allow for a seamless transition from a research demonstration project to a full-fledged service at the end of the five-year term:

La chose principale avec tout ceci, c'est quand tu regardes toute la manière dont ça été mis en place, à la fin des quatre ans si le gouvernement veut donner l'argent pour le continuer, on peut transférer l'argent du fédéral à la santé [en claquant des doigts]. On peut transférer les logements [en claquant des doigts]. On peut transférer la recherche [en claquant des doigts]. Elle s'est assurée de tout mettre tout ça en place, pour que ça puisse être mis dans notre système facilement. (Key player 21, 2010) ${ }^{11}$

One important aspect, however, could not be incorporated into governmental structures: housing. HF operates on the principle that the service user has the right to choose the living arrangement best suited to his or her individual needs and wants. One of the key elements of this approach is the concept of scattered housing. Efforts must be made to ensure that participants are not clustered together in order to foster a more natural living environment and facilitate community integration. Unfortunately, the already overladen social housing in the city did not correspond to the vision projected by this approach. The local team tackled the issue from a different angle, nonetheless with the same vigilance in terms of sustainability. Housing for participants was sought in the private market with careful attention to creating a solid network of reputable landlords with a good understanding of what it means to be homeless and live with mental health issues.

Overall, the most substantial aspect with regard to ensuring the program's sustainability was the care with which community members, organizations, and government officials were involved. A great deal of attention was paid to making the community aware of the initiative: "Faut qu'on garde le pulse de la communauté, puis il faut qu'on sache que la communauté sait qu'est-ce qui se passe, qu'elle est toujours au courant et heureuse avec ce qui se passe" (Key player 01, 2010). ${ }^{12}$ 


\section{DISCUSSION}

Program planning refers to the activities that occur prior to implementation of a program. There are two main approaches in this area: the expert-driven approach and the community-driven approach (Nelson et al., 2013). The former is top-down, wherein the problem to be addressed is defined by an outside agent and key program elements are determined according to evidence-based program models. The latter, on the other hand, is a bottom-up approach, where outside agents act to support the community in the identification of relevant issues. In this perspective, stakeholders strive to adapt or create programs fitting to community context (Barrera, Castro, \& Steiker, 2011; Laverack, 2000). Because both approaches focus on complementary and equally important aspects of the planning process, they are most often adopted simultaneously, creating a hybrid approach. The planning of At Home / Chez Soi used a hybrid model: the nature of the project was negotiated between the national team and the local sites (Nelson et al., 2013), but the project itself more closely resembles a top-down approach in that both the problem and key program elements were defined by experts in the field according to the growing body of literature demonstrating the benefits of HF models for homeless persons living with mental illness. There was, however, a certain amount of flexibility with regard to the criteria so as to meet the particular needs of the community in which the program was to be implemented.

As Trickett and colleagues (2011) caution, tensions developed when fidelity to evidence-based intervention (EBI) procedures clashed with the recognition that critical elements of the foundation research would be difficult or even impossible to implement, given Moncton's particular context. The face of homelessness in Moncton differs from that portrayed in the media, in that it is much less visible (Gaucher et al., 2010). Therefore, recruiting over 200 people experiencing absolute homelessness would have been virtually impossible, thus destining the project for failure. Fortunately the local team was able to negotiate a small number of exceptions to the definition of the target population and to provide input for modifications to the eligibility criteria of being precariously housed for all of the sites. This rectified the issue through what Barrera and colleagues (2011) refer to as "cultural adaptations" of EBI, wherein fidelity to the core elements of a given EBI are maintained, while certain aspects are modified so as to increase relevance for a particular group.

However, the national team's initial resistance in an effort to ensure uniformity across the sites led to delays in the development of other important aspects of the project. Consequently it is important for those involved in designing multisite complex interventions to anticipate the inevitable need to modify various program elements across intervention sites according to context by limiting key specifications or guidelines in the call for proposals so as to allow local planners sufficient flexibility in program development. It is equally important that community members be actively involved from the very beginning of a project, including in the development of specifications to be contained in the call for proposals, so as to ensure planners have an adequate understanding of the community's specificities and needs (Sylvestre et al., 1994).

Community engagement is regarded as essential to the development of the program planning process (Sylvestre et al., 1994; Trickett et al., 2011). In this particular case, delays related to definitional issues encountered in the early stages of planning led to the limited involvement of persons with lived experience. Moreover, key players perceived their involvement as limited to a small portion of the overall process. The 
lack of community involvement ultimately could have jeopardized buy-in (Barrera et al., 2011), yet the community as a whole rallied in support of the initiative. The level of support in this case can be attributed to pre-existing relationships between the limited number of professionals working in the field (due to the small size of the city) and their previous experience of working collaboratively due to a lack of resources for vulnerable persons. Furthermore, the site coordinator's knowledge with regard to the community context and her close ties with community leaders facilitated her ability to engage key players and to increase awareness in the community, skills that are deemed essential for achieving a long-term, sustainable community impact (Trickett et al., 2011). Findings in this article clearly demonstrate Moncton's uniqueness, particularly in terms of target population and context for interventions. They highlight both the importance and potential benefits of including a small city in a multisite demonstration project.

Although final decisions in terms of the planning and development of the project at the local level were made primarily by the coordinator, she came into the project with both strong connections at the community and government levels and a strong desire to ensure the overall success of the project, both of which were assets used to advocate for intervention conditions better able to meet the needs of the target population. Locock, Dopson, Chambers, and Gabbay (2001) stress that the support of a leader in itself is not a sufficient condition for change. On the contrary, for research evidence to be accepted, some process of local negotiation and adaptation is needed, requiring leaders to act as mediators and translators in this process of adapting guidelines so as to account for local circumstances, and generating the necessary consensus amongst key players. Furthermore, at this stage, the coordinator demonstrated an ability to successfully engage both key players and the community as a whole, primarily through the use of cooperative rather than confrontational tactics, but also through the development of positive personal relationships with those people (Markham, 1998). In the end, it was ultimately this strong and credible leadership that was paramount to the successful implementation of the demonstration project in the community. The findings in this article suggest that although maximal community involvement is ideal, a top-down approach can work with the right leadership.

The integration of a control group became a significant source of tension over the course of the planning and development phase. Randomized controlled trials, such as At Home / Chez Soi, imply the division of participants between a control group and an experimental group and are commonly believed to be the strongest way of testing the effectiveness of an intervention in real-life conditions (Barrera et al., 2011; Rossi, Lipsey, \& Freeman, 2004; Trickett, 2009). The integration of such a rigorous research design in Moncton, however, challenged the values and perspectives of many of the involved parties. It has been argued by both professionals and lay people that such experiments on humans are unethical. The most widely cited issue in this regard is that participants are called to sacrifice their own best interests for the benefit of future patients (Edwards, Lilford, Braunholtz, Jackson, Hewison, \& Thornton, 1998). Therefore, it has been argued that a trial is a sensible option only in cases where it is genuinely unknown whether a change in services will lead to better outcomes than the status quo and it is reasonable for the individuals in control groups to be subjected to existing standards (Freedman, 1987). A lack of consensus with regard to what constitutes the appropriate standard of care for control groups (Edwards, Lilford, \& Hewison, 1998) led key players to question the ethical implications of a control group in a context where existing resources and services for marginalized populations have proven to be problematic. Some struggled with the notion that randomization of clients to 
the control group could be detrimental to their overall well-being. On the contrary, Braunholtz, Edwards, and Lilford (2001) feel that clinical trials requiring the informed consent of the participants, such as At Home / Chez Soi, may have a beneficial effect on patients' outcomes both in terms of physical prognosis and psychological experience, perhaps due to unintended increased levels of care. Failure to test interventions against current realities could deprive disadvantaged populations of incremental improvements in health (Freedman, 1987), considering the low risk of negative outcomes; in this case, a control group was deemed necessary by the national team so as to ensure sufficient standardization and definition of core elements, thus allowing the national team to aggregate and compare data from the five cities. All things considered, it is important for future planners to acknowledge tensions that may arise due to competing agendas (Nelson et al., 2013) and maintain an open dialogue so as to find a common ground.

Johnson and colleagues (2004) argue the importance of such influential leadership and community engagement in terms of sustainability. It is believed that the stronger the ownership of the innovation among adopters, the more likely they are to advocate for its continuity, which undoubtedly was the case for key players in Moncton, whose concern surrounding the apparent lack of services for vulnerable populations in the area became the foundation on which the Moncton research demonstration project was built. While this aspect is typically ignored until the end of the innovation, it is suggested as most effective to commence sustainability activities during the initial design process (Pluye, Potvin, \& Denis, 2004). Key players, particularly the site coordinator, made great efforts from the project's onset to ensure the creation of a durable structure by integrating as many elements as possible into existing governmental structures, which have the capacity to carry out administrative functions related to the innovation responsively, effectively, and efficiently (Johnson et al., 2004).

In conclusion, it is important to note that researchers were limited in their ability to collect information from study participants. Firstly, due to key players' fragmented participation in the planning and development process, most were only able to offer pieces of information related to the part in which they were involved, limiting researchers' ability to obtain a clear and linear depiction of the events surrounding the planning and development of the local research demonstration project. Data collection seemed to be further limited by the respondents' willingness to provide researchers with only certain information or perceptions. In this respect, the city's small size and lack of resources undoubtedly had an important impact on the nature of relationships therein. At the time of data collection, interlaced connections amongst the key players and community organizations had long since been established. It was evident in this case, as is standard in small communities, that preserving harmony trumped the need to provide criticism, as constructive as it may be. For this reason, key players were very cautious not to be too critical during the interview process.

\section{CONCLUSION}

This article documents the planning and development phase of At Home / Chez Soi in Moncton, particularly the challenges that were met with regard to the adaptation of the target population, centralization of local coordination efforts, resistance in terms of the inclusion of a control group, and concerns surrounding the sustainability of the initiative. 
The Moncton site was able to successfully adapt participation criteria so as to better reflect local reality. Therefore, the sample was representative of the city's homeless population suffering from severe and persistent mental illness, thus ensuring that the study results will be relevant to policy-making in New Brunswick. We contend that such flexibility is required in multisite trials in order to maintain acceptable ecological validity. For various reasons, the planning and development of the project at the local level was ensured primarily by one person: the site coordinator. The latter proved highly capable of bringing the right people to the table, fostering stakeholder buy-in, and providing the necessary expertise to successfully plan and implement the demonstration project. A randomized control group was included in Moncton; this aspect was required by the national team and was non-negotiable. Because local stakeholders were faced with the option of providing much-needed services either to a hundred people or to none, they eventually managed to reconcile their ethical concerns with such a practice. Political decision-makers were kept engaged throughout the duration of the study by the site coordinator. For example, they sat on an advisory committee whose primary goal was to identify and use lessons learned to improve services for the target population. Furthermore, the ACT team was under provincial jurisdiction in an effort to ensure a seamless transition of services at the end of the study.

\section{NOTES}

1. A homeless person is someone who couchsurfs; it's someone in a special care home who shouldn't be there. These people sleep in prison because they have no home. It's not necessarily someone living in a cardboard box.

2. I think that the community was very, very open too, as well as community organizations. I think that that helped tremendously in the sense that those agencies already knew her, which helped tremendously in terms of making connections and being open to getting involved in a project like this.

3. She knew with her community experience, but mainly with her experience in Ottawa, she now knew how the system worked.

4. She was like: “Ok, you can't give me an ICM? You can't give me half the team I need. We can't do the job if we don't have the support. If you don't give us the staff we need, we can't do it."

5. I'm telling you that my involvement in the planning is very limited.

6. We were talking about the control group, and the discussion was, "Yes, and the 100 people in the control group will have service as usual." Together, at the same time, with the same pain in their eyes, the people all said, "There are no services."

7. The original research team declined an invitation to be interviewed about their involvement in the project.

8. The researcher was supposed to conduct the whole research; there were a lot of big issues surrounding the control group. Then, he decided he was not able to do it.

9. The Commission, them, they insisted that there be a control group for more convincing proof, for more backing.

10. It would have been much cheaper and much easier to hire people in the community for services. People from community organizations would have quickly joined the team and it would've caused a lot less headache. But, we said to ourselves: "Sure, we could do it like that, but at the end of four years, who is going to be there to support us? Who is going to be there to convince the government that it needs to continue?"

11. The important thing with all this is that when you look at the way everything was put in place, at the end of four years if the government wants to give money to continue it, money can be transferred from federal to health [snaps fingers]. We can transfer housing [snaps fingers]. We can transfer the research [snaps fingers]. She ensured that everything was put into place so that it could be easily integrated into our system.

12. We have to take the community's pulse, we have to know that the community knows what's going on, that it's always aware and happy with what's going on. 


\section{REFERENCES}

Aubry, T., Klodawsky, F., \& Coulombe, D. (2012). Comparing the housing trajectories of different classes within a diverse homeless population. American Journal of Community Psychology, 49(1-2), 142-55. doi:10.1007/ s10464-011-9444-z

Barrera, M., Castro, F. G., \& Steiker, L. K. H. (2011). A critical analysis of approaches to the development of preventive interventions for subcultural groups. American Journal of Community Psychology, 48(3-4), 439-54. doi:10.1007/ s10464-010-9422-x

Braunholtz, D. A., Edwards, S. J., \& Lilford, R. J. (2001). Are randomized clinical trials good for us (in the short term)? Evidence for a "trial effect."Journal of Clinical Epidemiology, 54(3), 217-24. doi:http://dx.doi.org/10.1016/ S0895-4356(00)00305-X

City of Moncton. (2002). Declaration by the city of Moncton city council: Official bilingualism. Retrieved from http://www.moncton.ca/Assets/Government+English/Bilingual+Services/Declaration+of+Official+Languages + English.pdf

City of Moncton. (2012). Moncton statistics. Retrieved from http://www.moncton.ca/Moncton_Our_Tide_is_Rising__ / Moncton_Statistics

Department of Justice Canada. (2012, June 29). Constitution Acts, 1867 to 1982. Retrieved from http://laws-lois.justice. gc.ca/eng/Const/index.html

Dewa, C. S., Durbin, J., Wasylenki, D., Ochocka, J., Eastabrook, S., Boydell, K. M., \& Goering, P. (2002). Considering a multisite study? How to take the leap and have a soft landing. Journal of Community Psychology, 30(2), 173-187. doi:10.1002/jcop.10001

Edwards, S. J., Lilford, R. J., Braunholtz, D. A., Jackson, J. C., Hewison, J., \& Thornton, J. (1998). Ethical issues in the design and conduct of randomised controlled trials. Health Technology Assessment (Winchester, England), 2(15), i-vi, 1-132. Retrieved from http://www.ncbi.nlm.nih.gov/pubmed/10194615

Edwards, S. J., Lilford, R. J., \& Hewison, J. (1998). The ethics of randomised controlled trials from the perspectives of patients, the public, and healthcare professionals. BMJ (Clinical Research Ed.), 317(7167), 1209-12. doi:http:// dx.doi.org/10.1136/bmj.317.7167.1209

Fédération canadienne des municipalités. (2011). La qualité de vie dans les municipalités canadiennes. Logement abordable et itinérance : tendances et enjeux. Rapport thématique numéro 4. Retrieved from http://www.fcm.ca/ Documents/reports/Trends_and_Issues_in_Affordable_Housing_and_Homelessness_FR.pdf

Fereday, J., \& Muir-Cochrane, E. (2008). Demonstrating rigor using thematic analysis: A hybrid approach of inductive and deductive coding and theme development. International Journal of Qualitative Methods, 5(1), 80-92. Retrieved from https://ejournals.library.ualberta.ca/index.php/IJQM/article/view/4411

Freedman, B. (1987). Equipoise and the ethics of clinical research. The New England Journal of Medicine, 317(3), 141-5. doi:10.1056/NEJM198707163170304

Gaetz, S. (2010). The struggle to end homelessness in Canada: How we created the crisis, and how we can end it. The Open Health Services and Policy Journal, 3, 21-26. Retrieved from http://www.homelesshub.ca/ResourceFiles/ rjhmnzr4.pdf

Gaucher, C., Albert, H., Savoie, L., \& Bâ, O. (2010). Ce qui se cache derrière la précarité domiciliaire : aborder les processus d'invisibilisation de l'itinérance à Moncton. Research in progress, Équipe Masculinités et Société, Université Laval, Québec.

Greater Moncton Homelessness Steering Committee. (2013). Experiencing homelessness: The sixth report card on homelessness in Greater Moncton, 2013. Retrieved from http://monctonhomelessness.org/documents/2013-6threport-card-gmhomelessness.pdf

Greene, J. C. (1994). Qualitative program evaluation: Practice and promise. In N. Denzin \& S. Lincoln (Eds.), Handbook of Qualitative Research. Thousand Oaks, CA: Sage.

Hulchanski, D., Campsie, P., Chau, S., Hwang, S., \& Paradis, E. (2009). Finding home: Policy options for addressing homelessness in Canada. Toronto, ON: Cities Centre Press. Retrieved from http://www.homelesshub.ca/ findinghome 
Human Resources and Social Development Canada. (2007). Community plan 2007-2009: Homelessness partnering strategy-Framework - Hamilton urban Aboriginal, Ontario. Retrieved from http://www.homelesshub.ca/resource/ community-plan-2007-2009-homelessness-partnering-strategy-framework-hamilton-urban

Johnson, K., Hays, C., Center, H., \& Daley, C. (2004). Building capacity and sustainable prevention innovations: A sustainability planning model. Evaluation and Program Planning, 27(2), 135-149. doi:10.1016/j. evalprogplan.2004.01.002

Katz, D. L., Murimi, M., Gonzalez, A., Njike, V., \& Green, L. W. (2011). From controlled trial to community adoption: The multisite translational community trial. American Journal of Public Health, 101(8), e17-27. doi:10.2105/ AJPH.2010.300104

King, J. A., Ross, P. A., Callow-Heusser, C., Gullickson, A. R., Lawrenz, F., \& Weiss, I. R. (2011). Reflecting on multisite evaluation practice. In A. King \& F. Lawrenz (Eds.), Multisite evaluation practice: Lessons and reflections from four cases. New Directions for Evaluation, No. 129. Retrieved from http://ca.wiley.com/WileyCDA/WileyTitle/ productCd-1118044495.html

Laverack, G. (2000). A planning framework for community empowerment goals within health promotion. Health Policy and Planning, 15(3), 255-262. doi:10.1093/heapol/15.3.255

Locock, L., Dopson, S., Chambers, D., \& Gabbay, J. (2001). Understanding the role of opinion leaders in improving clinical effectiveness. Social Science \& Medicine, 53(6), 745-757. doi:10.1016/S0277-9536(00)00387-7

Markham, S. K. (1998). A longitudinal examination of how champions influence others to support their projects. Journal of Product Innovation Management, 15(6), 490-504. doi:10.1111/1540-5885.1560490

Mental Health Commission of Canada. (2012). Issue: Housing and homelessness. Retrieved from http://www.mental healthcommission.ca/English/Pages/homelessness.aspx?routetoken=5f2200f72fcff7381523d83690c70209\& terminitial $=23$

Nelson, G. (2010). Housing for people with serious mental illness: Approaches, evidence and transformative change. Journal of Sociology and Social Welfare, XXXVII(4), 123-146. Retrieved from http://connection.ebscohost.com/c/ articles/56545265/housing-people-serious-mental-illness-approaches-evidence-transformative-change

Nelson, G., Aubry, T., \& Lafrance, A. (2007). A review of the literature on the effectiveness of housing and support, assertive community treatment, and intensive case management interventions for persons with mental illness who have been homeless. The American Journal of Orthopsychiatry, 77(3), 350-61. doi:10.1037/0002-9432.77.3.350

Nelson, G., Macnaughton, E., Goering, P., Dudley, M., O’Campo, P., Patterson, M., ... Vallée, C. (2013). Planning a multi-site, complex intervention for homeless people with mental illness: The relationships between the national team and local sites in Canada's At Home / Chez Soi project. American Journal of Community Psychology, 51(34), 347-58. doi:10.1007/s10464-012-9554-2

Padgett, D., Gulcur, L., \& Tsemberis, S. (2006). Housing First services for people who are homeless with cooccurring serious mental illness and substance abuse. Research on Social Work Practice, 16(1), 74-83. doi: $10.1177 / 1049731505282593$

Parliament of Canada. (2012). Defining and enumerating homelessness in Canada (PRB 08-30E). Current Publications: Social Affairs and Population. Retrieved from http://www.parl.gc.ca/content/lop/researchpublications/prb0830-e. htm

Pluye, P., Potvin, L., \& Denis, J.-L. (2004). Making public health programs last: Conceptualizing sustainability. Evaluation and Program Planning, 27(2), 121-133. doi:10.1016/j.evalprogplan.2004.01.001

Raghavan, R., Bright, C. L., \& Shadoin, A. L. (2008). Toward a policy ecology of implementation of evidence-based practices in public mental health settings. Implementation Science: IS, 3(1), 26. doi:10.1186/1748-5908-3-26

Rossi, P., Lipsey, M., \& Freeman, H. E. (2004). Program evaluation: A systematic approach. Thousand Oaks, CA: Sage.

Roy, S., Hurtubise, R., Bélanger, C., Lemetayer, F., Morin, D., \& Morin, P. (2003). Itinérance en Montérégie. Comprendre le phénomène et identifier les besoins. Retrieved from http:/www.rapsim.org/docs/CRI-Rapport-Monteregie-2003. pdf

Statistics Canada. (2007, February 13). Population by mother tongue, by census metropolitan area, excluding institutional residents (2011 Census) (St. John's, Halifax, Moncton, Saint John). Retrieved June 29, 2012 from http:// www.statcan.gc.ca/tables-tableaux/sum-som/101/cst01/demo12a-eng.htm 
Sylvestre, J. C., Pancer, S. M., Brophy, K., \& Cameron, G. (1994). The planning and implementation of governmentsponsored community-based primary prevention: A case study. Canadian Journal of Community Mental Health/ Revue Canadienne de Santé Mentale Communautaire, 13(2), 189-95. Retrieved from http://www.ncbi.nlm.nih. gov/pubmed/10151075

Trickett, E., Beehler, S., Deutsch, C., Green, L., Hawe, P., McLeroy, K., ... Trimble, J. (2011). Advancing the science of community-level interventions. American Journal of Public Health, 101(8), 1410-1419. Retrieved from http:// web.b.ebscohost.com/abstract?direct $=$ true \&profile $=$ ehost\&scope $=$ site \&authtype $=$ crawler\&jrnl $=00900036 \& A N$ $=64155917 \& \mathrm{~h}=$ GFAaL28zpihLNZpeeTA9B4j4gs9BNTCdkilUXpWyrjKy25rePc478UrOHqhbt7nbxugCIgbXs S5Vvwgm8WEqzA==\&crl=c

Trickett, E. J. (2009). Multilevel community-based culturally situated interventions and community impact: An ecological perspective. American Journal of Community Psychology, 43(3-4), 257-66. doi:10.1007/s10464-009-9227-y 